\title{
LA INTERPRETACIÓN ANTROPOLÓGICA DE LA FENOMENOLOGÍA DEL ESPÍRITU. APORTES Y PROBLEMAS ${ }^{1}$
}

\author{
Luis Mariano de la Maza \\ Pontificia Universidad Católica de Chile \\ sde14@puc.cl
}

\begin{abstract}
Resumen
Este artículo se refiere a una línea de interpretación de la Fenomenología del Espíritu de Hegel que tiene en Alexandre Kojève a su exponente más conocido e influyente. En ella se privilegian los aspectos antropológico-existenciales e histórico-políticos por sobre los aspectos lógico-sistemáticos de la obra. La exposición se divide en dos partes. La primera está dedicada a la lectura de Hegel realizada por Kojève en su célebre curso dictado entre 1933-1939 en la École Practique des Hautes Études de París, y la segunda se ocupa de su aporte a cinco filósofos directamente influidos por su interpretación. Finalmente concluye con una breve evaluación de estas lecturas.
\end{abstract}

Palabras clave: Fenomenología del Espíritu, reconocimiento, fin de la Historia, religión, saber absoluto, Hegel, Kojève, Hyppolite, Bataille, Sartre, Weil, Fukuyama.

\section{Abstract}

This article refers on a kind of interpretation of Hegel's Phenomenology of Spirit that has in Alexandre Kojève his more known and influential exponent. She favoured the anthropologic-existential and historical-political aspects over the logical-systematic aspects of the work. The exposition is divided in two parts. The first one is dedicated to Hegel's reading realized by Kojève in his famous course dictated between 1933-1939 in the École Practique des Hautes Études of Paris, and the second one deals with his contribution to five philosophers directly influenced by this interpretation. It concludes with a brief evaluation of these readings.

KEY WORDS: Phenomenology of Spirit, Recognition, End of History, Religion, Absolute knowledge, Hegel, Kojève, Hyppolite, Bataille, Sartre, Weil, Fukuyama.

1 Este trabajo forma parte de un proyecto de investigación financiado por Fondecyt $\left(\mathrm{N}^{\circ}\right.$ 1100815). Una primera versión, más breve, fue presentada en el Simposio Internacional Reconocimiento, libertad y justicia. La actualidad de la filosofía práctica de Hegel en Latinoamérica, organizado por la Universidad Autónoma de la Ciudad de México, en colaboración con la Fundación Konrad Adenauer, 17-19 de mayo de 2011. Agradezco la autorización para publicar esta versión modificada. 


\section{La lectura de Kojève}

\subsection{Antecedentes}

$\overline{R A}$

Entre 1933 y 1939, Alexandre Kojève dictó cursos sobre la Fenomenología del Espíritu de Hegel en la École Practique de Hautes Études, a los que asistieron, entre otros, Jacques Lacan, Raymond Aron, Georges Bataille, Jacques y Maurice Merleau-Ponty, Eric Weil, Gaston Fessard, Jean Hyppolite. Una parte de aquellas clases fueron reunidas por uno de los asistentes, el matemático Raymond Queneau, y publicadas en 1947 con el título Introduction à la lecture de Hegel.

Kojève había asistido en 1932 a los cursos impartidos por Alexandre Koyré sobre la filosofía religiosa de Hegel en la misma École Practique des Hautes Études ${ }^{2}$. Cuando éste debió viajar a El Cairo por una oferta de trabajo, le ofreció a Kojève continuar con la parte de su curso correspondiente a la Fenomenología del Espíritu. Pero la deuda de Kojève con Koyré no es solo laboral, sino que alcanza también los fundamentos de su interpretación de la obra de Hegel, como lo reconoce aquél en el Resumen del Curso 1933-1934:

Mi conferencia ha sido concebida como una prolongación del curso de Koyré sobre la filosofía religiosa de Hegel. Koyré ha analizado los textos anteriores a la Fenomenología del Espíritu. Yo he consagrado mi conferencia al estudio de la Fenomenología siguiendo el método de interpretación de Koyré y basándome en las ideas directrices de su Curso ${ }^{3}$.

Las ideas directrices a las que se refiere Kojève se encuentran expuestas en el artículo de 1934, "Hegel à Jena", reproducido en su libro Ėtudes d'histoire de la pensee philosophique ${ }^{4}$. Koyré presenta el concepto hegeliano del absoluto como una síntesis de la historia y de la teología, una síntesis entre eterno movimiento y eterno cumplimiento. Con ello pone en el centro del pensamiento de Hegel la humanización del absoluto y del tiempo. Pero al mismo tiempo, Koyré considera necesario distinguir dos formas distintas de la temporalidad: por un lado está el tiempo de las cosas, que es un tiempo pasado, espacializado y fijo, y por otro lado está el tiempo del hombre, que es histórico, porque se realiza en función del futuro y no del pasado. Por lo mismo, la existencia del hombre es dialéctica, mientras que la naturaleza no lo es:

El tiempo hegeliano es ante todo un tiempo humano, el tiempo del hombre, ese mismo ser extraño que 'es lo que no es y no es lo que es', ser que se niega lo

Antes de esos cursos, la filosofía de Hegel era poco conocida en Francia, a pesar de que Jean Wahl había publicado en 1929 un estudio sobre la "conciencia desdichada": Le malheur de la conscience dans la philosophie de Hegel.

Kojève, A. (1947), p. 57; DAE, p. 63.

Koyré, A. (1971), pp. 135-174. 
que es en provecho de lo que todavía no es, ser que parte del presente, lo niega, buscando realizarse en el futuro [...] Y porque el tiempo hegeliano es humano también es dialéctico, así como porque es uno y el otro es esencialmente histórico ${ }^{5}$.

Por otra parte, Koyré plantea un problema de la filosofía hegeliana que Kojève tratará de su resolver a su modo. Si el tiempo humano alcanzara su cumplimiento y realización, ello implicaría la anulación del futuro, y con ello se acabaría el movimiento de la historia. Pero si el tiempo del hombre no se realizara, entonces el pensamiento filosófico verdadero sobre la historia no tendría sentido. Eso quiere decir, entonces, que la filosofía de la historia de Hegel debe pagar el precio de la abolición de la dialéctica histórica o el fin de la historia, y el retorno del hombre al reino de la naturaleza con la consiguiente pérdida de su libertad.

Kojève reconoce la seriedad del dilema planteado por Koyré, pero, como bien señala Dominique Auffret, en vez de intentar disolverlo decide radicalizarlo, convirtiéndolo en una clave interpretativa de la Fenomenología ${ }^{6}$.

\subsection{El sentido y el movimiento de la Fenomenología}

Kojève distingue entre una interpretación antropológica y una interpretación metafísica de la Fenomenología del espíritu. La primera consiste en una lectura de los siete primeros capítulos del libro "como una descripción de la Autoconciencia, es decir, de las diferentes maneras en que el Hombre se comprende a sí mismo". La segunda, en cambio, consiste en "leer los mismos siete capítulos como descripción de la Conciencia-exterior, esto es, de las diferentes maneras en que el Hombre toma conciencia del Mundo y del Ser en general". Esta interpretación metafísica sería objeto de un resumen que ofrece Hegel al comienzo del capítulo VIII y final sobre el saber absoluto ${ }^{7}$.

Al final de los primeros siete capítulos aparece el sabio como una "figura del espíritu", todavía contrapuesta al mundo. Para suprimir esa oposición hay que volver a pensar ese proceso integrando las distintas actitudes cognoscitivas acerca de la realidad cosificada o del Gegenstand. De ese modo termina la distinción entre el sabio y la ciencia: su unidad constituye la sabiduría realizada ${ }^{8}$. Pero ello no puede ocurrir en cualquier momento, sino solo en aquel momento en que exista la realidad total o absoluta que el saber absoluto debe revelar, es decir la plena realización histórica del hombre:

Koyré, A. (1971), pp. 162 s. (la traducción es mía).

Auffret, D. (1990), pp. $335 \mathrm{~s}$.

Kojève, A. (1947), pp. 308 s.; CAA, p. 56.

Kojève, A. (1947), pp. 322-328; CAA, pp. 72-79. 
La Ciencia total sólo puede resultar de un esfuerzo total del Hombre, es decir del conjunto del esfuerzo humano colectivo realizado por la evolución perfecta de la Historia universal ${ }^{9}$.

Kojève afirma repetidamente que el método hegeliano no es dialéctico, sino fenomenológico, en el sentido husserliano ${ }^{10}$, es decir, un método "científico" que se limita a contemplar y describir la realidad del ser. Ahora bien, dado que esa realidad es dialéctica, la descripción de la misma es también dialéctica. Pero lo es derivadamente, como consecuencia de su carácter revelador del ser. "El movimiento de la Ciencia sólo es dialéctico en la medida en que reproduce o describe la Dialéctica de la realidad" Pero ¿qué quiere decir que el ser o lo real es dialéctico? Kojève lo explica citando el $\S$ 79 de la $3^{\text {a }}$ edición de la Enciclopedia de las ciencias filosóficas en el que se introduce la primera parte, dedicada a la Lógica. En ese texto, Hegel sostiene que "lo lógico" presenta tres aspectos: el abstracto o propio del entendimiento, el dialéctico o racionalnegativo, y el especulativo o racional-positivo. Según Kojève, estos tres aspectos corresponden a las "categorías ontológicas primordiales y universales" de identidad, negatividad y totalidad ${ }^{12}$. La primera se refiere al acuerdo perfecto del pensamiento consigo mismo o la ausencia de toda contradicción interna del entendimiento. Este aspecto es verdadero, pues sin él no sería posible hacer ninguna afirmación coherente sobre lo real, pero solo lo es parcialmente, ya que las cosas no son solo lo que son, sino también lo que no son. No son solo igualdad consigo mismas, sino también negación de sí mismas como algo distinto de lo simplemente dado ${ }^{13}$.

Este aspecto negativo presupone la acción libre, pues no es sino a través de ésta que lo simplemente dado deja de ser tal. Esta acción se realiza de dos maneras: la lucha y el trabajo, y por lo tanto depende esencialmente del hombre ${ }^{14}$. En este punto, la interpretación de Kojève se distancia críticamente de Hegel, pues no admite como éste que la negatividad y, por ende, el momento dialéctico de lo real pueda darse también en la naturaleza como tal. A partir de la introducción de la categoría fundamental de la negatividad o de la acción, "el ser verdadero del Hombre", se desprenden, según Kojève, todos los rasgos característicos de la dialéctica hegeliana ${ }^{15}$.

El tercer aspecto de lo lógico se refiere a la totalidad o al "Ser real concreto", que implica la identidad y la negatividad en tanto que superadas en lo que tienen de parciales. Kojève recurre a este respecto a la distinción entre tesis, antítesis y síntesis, que como tal no se encuentra en Hegel:

Kojève, A. (1947), p. 329; CAA, p. 81.

Kojève, A. (1947), p. 38, 57; DAE, pp. 39, 63.

Kojève, A. (1947), p. 480; DRIM, p. 48.

Kojève, A. (1947), pp. 447 s., 470-477; DRIM, pp. 7 s., 36-45.

Kojève, A. (1947), p. 533; IMH, p. 20.

Kojève, A. (1947), pp. 464 ss.; DRIM, pp. 29 ss.

Kojève, A. (1947), p. 533; IMH, p. 20. 
Si la Tesis describe el Ser (Sein) de lo Real, la Antítesis describe su Acción (Tun); y también la conciencia que tiene de sí mismo y que sólo es el desdoblamiento de lo Real en algo real que es negado en su ser dado [...] y en algo real que niega ese ser dado por una acción espontánea. En fin, la Síntesis describe al Ser en tanto que Totalidad. Ella revela un ser (dialéctico) considerándolo como resultante de su acción, por la cual se ha suprimido en tanto que ser dado, del cual ha tomado conciencia en y por esa misma supresión" ${ }^{16}$.

La totalidad, tal como la interpreta Kojève, no es monista como en Hegel, justamente porque el momento de la negatividad solo puede ser introducido por una realidad que es esencialmente distinta a la realidad de la naturaleza. A su juicio, la totalidad es dialéctica mediatamente, a través del hombre, y únicamente porque éste lo es ${ }^{17}$. Hegel cometería el error de derivar de la dialecticidad de la totalidad la dialecticidad de sus dos momentos constitutivos, es decir, tanto del hombre como de la naturaleza. Pero esta última no pude ser dialéctica, porque no es creadora ni es histórica como el hombre, que se caracteriza esencialmente por ser una negación activa de la naturaleza. Por ello, Kojève llama a corregir la filosofía de Hegel en un sentido dualista, tarea que considera parcialmente anticipada por Kant y el Heidegger de Ser y Tiempo ${ }^{18}$.

No obstante, Kojève no pretende defender un mero actualismo subjetivo, en el sentido de que el hombre sea una realidad ajena a la naturaleza. En tanto que aparece en el mundo natural como un ser corpóreo posee también caracteres fijos, "es un 'animal específicamente determinado' que vive en el seno de la naturaleza y que tiene allí su 'vínculo natural' (topos)"'19. En ese sentido, el hombre no nace verdaderamente libre, sino que se hace libre de modo activo por medio de la lucha y el trabajo que realizan la negación de lo dado, que incluye su propia realidad natural ${ }^{20}$.

\subsection{Autoconciencia, reconocimiento y muerte}

Según Kojève, Hegel habría llegado mucho más lejos que René Descartes, el primer filósofo moderno en reflexionar sobre la subjetividad. Descartes solo fijó su atención en el pensamiento y descuidó el "yo" específicamente humano, que es más que pensamiento. Para que haya una existencia verdaderamente humana se requiere autoconciencia, es decir, una mismidad humana que se revela cuando el hombre dice "yo"21.

Ahora bien, la constitución de la autoconciencia humana tiene algunos requisitos previos. En primer lugar, la existencia de una conciencia, que según la interpretación de Kojève corresponde al conocimiento del ser que se revela a través de la palabra.

16 Kojève, A. (1947), pp. 480 s.; DRIM, p. 49 s.

17 Kojève, A. (1947), p. 482; DRIM, p. 52.

18 Kojève, A. (1947), pp. 485 ss, Nota; DRIM, pp. 56 ss., Nota 15.

19 Kojève, A. (1947), p. 491; DRIM, p. 63.

20 Kojève, A. (1947), pp. 492-494; DRIM, pp. 64-67.

$21 \quad$ Kojève, A. (1947), p. 165; DAE, p. 186. 
Esta contemplación del ser es insuficiente, sin embargo, para acceder al yo. Para que la palabra revele al yo se requiere algo más: el deseo. El hombre que desea ya no está absorbido en la contemplación de las cosas, sino que está referido a sí mismo. La cosa se le aparece entonces como un "objeto", como una realidad exterior, que no está en él ni es él, sino un no-yo. El deseo quiere suprimir el ser independiente de mí para hacerlo mío. Por lo tanto, para que haya autoconciencia humana se requiere un yo negador que transforma activamente el ser deseado ${ }^{22}$.

La diferencia esencial del hombre con el animal radica en que el animal no es capaz de elevarse por encima de la naturaleza, a la que niega en su deseo animal. Solo llega hasta el sentimiento de sí, pero no a la conciencia de sí. Inmediatamente que satisface el deseo recae de nuevo en la naturaleza. Para la autoconciencia, el deseo no debe llevar simplemente a un ser dado, sino a un no-ser. Desear lo dado es depender de él; en cambio desear lo que no es, es liberarse del ser, es ser libre y autónomo. Por lo tanto, el deseo que constituye al hombre está dirigido al no-ser. Lo que desea el deseo humano -afirma Kojève- es el deseo como tal, sin contenido. Este deseo está dirigido hacia otro deseo humano, es decir, otro vacío igualmente ávido, otro yo.

Para ser humano, el hombre debe actuar no con el fin de someter una cosa, sino de someter otro Deseo (de la cosa). El hombre que desea humanamente una cosa actúa no tanto para apoderarse de la cosa sino para hacer reconocer por otro su derecho -como se dirá más tarde- sobre esa cosa, para hacerse reconocer como propietario de la cosa. Y esto -a la postre- para hacer reconocer por el otro su superioridad sobre el otro. Sólo el Deseo de tal Reconocimiento, sólo la Acción que se deriva de tal Deseo, crea, realiza y revela un Yo humano, no biológico ${ }^{23}$.

La realización de la autoconciencia humana exige, por tanto, admitir la existencia de múltiples deseos que pueden desearse mutuamente, de los cuales cada uno quiere negar y someter, asimilar o hacer suyo a los demás en tanto que deseos. Esta pluralidad de deseos de reconocimiento no puede conducir a otra cosa que a la lucha de vida o muerte. El hombre arriesgará su vida biológica para obtener satisfacción de su deseo no-biológico. Hegel y Kojève sostienen que el hombre que es incapaz de poner en peligro su vida para alcanzar fines no inmediatamente vitales, como es el puro prestigio, no es verdaderamente humano ${ }^{24}$.

Ahora bien, para que la lucha por el reconocimiento pueda obtener lo que persigue es necesario que ella no concluya en la muerte de los contrincantes, pues aunque uno de ellos sobreviva no podrá ser reconocido por un muerto. La realidad humana exige que vivan las dos autoconciencias en pugna, para que una pueda reconocer a la otra. La lucha termina entonces en el momento en que una de las dos autoconciencias cede ante la otra porque no está dispuesta a llegar hasta el fin. Aquella de las dos autoconciencias que 
no es capaz de sobreponerse al instinto biológico de conservación deviene, en lenguaje hegeliano, esclava de aquella otra que desprecia la muerte y que se convierte, por lo mismo, en amo dominador de la autoconciencia vencida. La existencia del esclavo queda reducida a tener que trabajar para el amo, mientras que el amo sigue existiendo como un guerrero, pero no trabaja. Como Aristóteles, Hegel divide a los hombres en amos y esclavos, pero con la diferencia esencial de que para él estas condiciones no son algo natural sino, por el contrario, una división que se crea en el tiempo mediante una acción voluntaria que puede ser cambiada por otras acciones igualmente voluntarias, aunque según Kojève solo el esclavo puede cambiar y llegar a ser verdaderamente humano ${ }^{25}$.

Para Kojève, la filosofía de Hegel es una filosofía de la muerte ${ }^{26}$, puesto que solo un ser mortal, radicalmente finito, puede ser libre. La muerte es la otra cara de la libertad. Si el hombre fuera inmortal y sobreviviera a su muerte biológica, no sería libre. Solo puede haber libertad donde el conjunto de las posibilidades no son todas las posibilidades en general, y lo que está fuera de ese conjunto no sea una imposibilidad absoluta. En otras palabras, el hombre es libre porque posee una historia en la que puede escoger libremente posibilidades particulares entre la infinitud de posibilidades existentes, pero sin poder realizarlas todas, por no tener tiempo para ello al estar limitado por su muerte ${ }^{27}$.

Kojève insiste en la identidad de la libertad y la muerte, o del dominio absoluto y la alteridad absoluta, porque su interpretación está fuertemente influida por Ser y tiempo de Martin Heidegger. Pero le añade un elemento ciertamente ajeno al pensamiento heideggeriano, al relacionar la finitud humana con la dialéctica:

La Muerte es una finitud dialéctica. El ser dialéctico, es decir, el Hombre, es el único ser mortal, en sentido lato. La muerte de un ser humano difiere esencialmente del 'fin' de un animal o de una planta, así como de la 'desaparición' de una cosa por simple 'desgaste'28.

\subsection{La historia}

Al describir al hombre como un ente dialéctico, Hegel no solo lo define por su acción negadora de todo lo dado, sino también por el carácter creador de esa acción, que produce una obra (Werk) que permanece, y sirve de signo de su realidad. La conservación de lo negado en la obra humana se efectúa por medio del recuerdo de quien lo ha negado: "Por eso el Hombre es una realidad humana dialéctica solo en la medida en que es histórico, lo que no se alcanza sino recordando su pasado superado"29.

25 Kojève, A. (1947), pp. 30, 34, 174 s., 179 s.; DAE. pp. 32, 36, 198, 204.

26 Kojève, A. (1947), p. 539; IMH, p. 31.

27 Kojève, A. (1947), pp. 519 s.; DRIM, pp. 99 s.

28 Kojève, A. (1947), p. 512; DRIM, p. 90.

29 Kojève, A. (1947), p. 505; DRIM, p. 80. 
Por otra parte, Hegel concibe la individualidad que caracteriza la existencia humana como una síntesis de lo particular y de lo universal. Lo particular es lo tético o idéntico a sí mismo, mientras que lo universal se refiere a la negación o antítesis de lo particular, por ejemplo, de la raza, la nacionalidad, la clase social, etc., para ser reconocido por el Estado como ciudadano. En el plano fenoménico esta individualidad se manifiesta como realización activa del deseo humano de reconocimiento, lo cual no puede cumplirse sino en la sociedad donde el hombre interactúa con los otros hombres que le proporcionan dicho reconocimiento viviendo y actuando como ciudadanos del Estado $^{30}$. Pero el Estado no puede satisfacer este deseo de reconocimiento mientras la historia, que según Kojève es justamente el proceso de satisfacción progresiva del deseo de reconocimiento, no haya llegado a su final ${ }^{31}$. Ahora bien, el fin de la historia coincide con la existencia de un Estado homogéneo y universal:

Pues en el Estado homogéneo las 'diferencias especificas' (Besonderheiten) de clase, raza, etc., son 'suprimidas' y ese Estado se relaciona entonces directamente con lo particular en tanto que tal, que es reconocido como ciudadano en su propia particularidad. Y ese reconocimiento es verdaderamente universal, pues por definición, el Estado engloba el conjunto del género humano (aun en su pasado, por la tradición histórica total que ese Estado perpetúa en el presente y en su prorvenir, puesto que el porvenir no difiere en adelante del presente donde el Hombre ya está plenamente satisfecho) $)^{32}$.

A este resultado se ha llegado ya, sostiene Kojève, si es que el deseo de reconocimiento agota todas las posibilidades humanas, pero esta suposición solo puede hacerse cuando se tiene un conocimiento completo y perfecto del hombre, es decir, un saber absolutamente verdadero, universal y definitivo, que es justamente el saber que solo puede ser alcanzado al final de la historia. Nos encontramos frente a un círculo, pues el saber absoluto se alcanza al final de la historia, el cual se reconoce, a su vez, cuando se llega al saber absoluto. Pero esta circularidad es también la del Sistema de la Ciencia mediante el cual Hegel puede describir la totalidad de lo real ${ }^{33}$.

Según la interpretación de Kojève, fuertemente influida en este punto por Karl Marx, la historia comienza con la primera lucha que desembocó en la aparición de un amo y de un esclavo ${ }^{34}$. Toda la historia es una historia de la interacción entre amos que luchan y esclavos que trabajan, y solo se detiene en el momento en que desaparece esta oposición, es decir en el momento en que no hay más amos porque no hay esclavos, ni esclavos, porque no hay amos. El sentido de las guerras de Napoleón, en tanto que cumplimiento de la Revolución Francesa, es justamente realizar este acabamiento de la

32

Kojève, A. (1947), p. 75; DAE, pp. 82.

Kojève, A. (1947), pp. 174 s., 184 s., 467 s.; DAE, pp. 198, 210 s., DRIM, pp. 33 s.

Kojève, A. (1947), p. 508; DRIM, p. 84.

Kojève, A. (1947), pp. 468 s.; DRIM, pp. 34 s.

Kojève, A. (1947), pp. 172, 521; DAE, p. 194, DRIM, pp. 101 s. 
historia por la supresión dialéctica del amo y del esclavo ${ }^{35}$. Kojéve sostiene que Hegel tiene la conciencia de ser el único filósofo que comprende la historia universal en su conjunto y el sentido de la existencia de Napoleón, que entraba a cañonazos en la ciudad de Jena en el mismo momento en que Hegel terminaba de escribir su Fenomenología. Además, es un filósofo dotado de un saber absoluto, es decir, universal y eternamente válido, justamente por el hecho de vivir en tiempos de Napoleón y de ser el único capaz de comprenderlo ${ }^{36}$.

\subsection{La religión y el saber absoluto}

Según Kojève, la inmortalidad o la creencia en Dios serían incompatibles con la realización de la individualidad humana y harían que el hombre viviera en contradicción consigo mismo, o, en palabras de Hegel, viviera en el desdoblamiento y fuera una "conciencia infeliz" "37. Si bien Hegel coincide con el cristianismo al decir que lo absoluto no es sustancia idéntica ni naturaleza, sino espíritu, para el cristianismo el espíritu absoluto es un Dios trascendente, eterno e infinito, mientras que para Hegel es el hombre en el mundo, esencialmente finito o mortal ${ }^{38}$. Mientras que el Dios de la teología cristiana es un ser eternamente idéntico consigo mismo que se revela en el mundo, el hombre de Hegel es la nada que anihila al ser dado en el Mundo y se anihila a sí mismo en tanto que tiempo real histórico por el aniquilamiento de lo dado ${ }^{39}$.

Kojève contrapone la posición de Hegel y la de Platón respecto de la sabiduría. Para el primero no solo es realizable, sino que ya se ha realizado en quien ha hecho el camino de la Fenomenología del espíritu. Platón, en cambio, aunque acepta el ideal del sabio como fin de la existencia humana, sostiene que el filósofo no podrá realizar nunca ese ideal. Según Kojève, la oposición entre Hegel y Platón no es una oposición al interior de la filosofía, sino una oposición entre filosofía y teología, o entre sabiduría y religión ${ }^{40}$. Para el religioso solo se puede llegar a la sabiduría mediante un salto que rompe la continuidad y la lógica interna del proceso filosófico. Este salto puede darse en cualquier momento histórico y bajo cualesquiera circunstancias reales, pues para ello basta que Dios se revele. En cambio, para el filósofo aceptar el ideal del sabio negando al mismo tiempo que pueda ser realizado equivaldría a subordinar la filosofía a la teología. Por ello, la afirmación de la sabiduría o de la filosofía que conduce hasta ella supone destruir la religión mediante su interpretación antropológica ${ }^{41}$. Ahora bien, esta destrucción o ateísmo del sabio no puede nacer de otra religión que no sea la cristiana, puesto que, según Kojève, Hegel aplica al hombre la idea cristiana de Dios.

Kojève, A. (1947), pp. 562 s.; IMH, pp. 71 s.

Kojève, A. (1947), p. 164; DAE, pp. 184 -5.

Kojève, A. (1947), p. 526; DRIM, p. 108.

Kojève, A. (1947), p. 573; IMH, p. 91.

Kojève, A. (1947), p. 574; IMH, p. 92.

Kojève, A. (1947), pp. 284-287; CAA, pp. 24-27.

Kojève, A. (1947), pp. 301 s.; CAA, p. 47. 
En la teología cristiana, la religión se supera a sí misma en tanto que religión, pues es la teología del Dios que muere para que el hombre se realice como tal ${ }^{42}$. Por eso la teología cristiana precede a la ciencia ${ }^{43}$.

\subsection{Circularidad y eternidad del saber absoluto}

La circularidad es la condición necesaria y suficiente de la verdad absoluta, es decir, completa, universal y definitiva. Para el filósofo, la circularidad del saber es la garantía de su carácter total y cerrado, es decir, absoluto, y no se da en cualquier momento, sino al final de la historia, cuando se han completado todas las condiciones que lo hacen posible ${ }^{44}$. Pues esta circularidad no se refiere solo al contenido ideal o abstracto de la verdad, sino que tiene también, según la interpretación de Kojève, un aspecto real. Este aspecto real se refiere a la existencia del sabio, la que tiene que ser "circular" para que el saber que revela su existencia sea también circular, es decir, una verdad absoluta. Y la circularidad de la existencia real del sabio solo se da en el Estado universal y homogéneo, en el que la acción de todos es también la acción de cada uno, "donde cada uno es para y por el todo, y el todo para y por cada uno" ${ }^{45}$.

En la segunda parte del capítulo VIII sobre el Saber absoluto, Hegel plantea la cuestión de la relación entre la ciencia como saber conceptual y el tiempo. Kojève sitúa la posición de Hegel en contraposición a otras variantes posibles. La primera de ellas, representada por Parménides, es la que no relaciona, sino que identifica el concepto con la eternidad. La segunda posición sostiene que el concepto es eterno, pero no se identifica con la eternidad, por lo que admite dos relaciones posibles: 1) el concepto eterno se refiere a la eternidad, ya sea desde fuera del tiempo (Platón) o en el tiempo (Aristóteles); o bien 2) el concepto eterno se refiere al tiempo (Kant). La tercera posibilidad, que es la que Kojève atribuye a Hegel, sostiene que el concepto se identifica con el tiempo, y por lo tanto no se relaciona ni con la eternidad ni con el tiempo. Por último, según la cuarta posibilidad, el concepto es temporal, por lo cual no hay nada permanente, ni siquiera el tiempo mismo. Esta última posición corresponde al escepticismo, pues hace imposible todo conocimiento verdadero, al no aceptar que exista nada definitivo ${ }^{46}$.

Según Kojeve, lo que hace de Hegel un gran filósofo, a la altura de Platón, Aristóteles y Kant, es la identificación de concepto y tiempo, porque ello es lo que le permite dar cuenta de la historia o de la existencia del individuo libre e histórico ${ }^{47}$. El concepto hegeliano de la ciencia se resumiría en la siguiente afirmación: "El tiempo es

42

43

44

46

Kojève, A. (1947), pp. 192 s. 299s.; DAE, pp. 220 s., CAA, pp. 44 s.

Kojève, A. (1947), pp. 331 s., CAA, pp. 83 s.

Kojève, A. (1947), p. 393; CAA, p. 162.

Kojève, A. (1947), p. 288; CAA, p. 29 s.

Kojève, A. (1947), pp. 336-338;CAA, pp. 89-92.

Kojève, A. (1947), p. 365; CAA, p. 126. 
el concepto mismo que existe ahi" ${ }^{48}$. El tiempo del que habla aquí Hegel es el tiempo histórico, no el biológico o cósmico. En Hegel, el movimiento del tiempo no va del pasado al porvenir, pasando por el presente, sino que, por el contrario, "se engendra en el Porvenir y va hacia el Presente transitando por el Pasado, [...] estructura propia del tiempo específicamente humano, y por lo tanto histórico" ${ }^{49}$. El movimiento que engendra el porvenir, y con ello la historia, es el que nace del deseo específicamente humano, es decir, del deseo de reconocimiento, dirigido sobre otro deseo. La realización de este deseo exige negar algo pasado, y la manera en la que el pasado ha sido negado en función del porvenir determina el presente humano o histórico. En este sentido puede afirmar Kojève que "el Tiempo es el Hombre y el Hombre es el Tiempo" ${ }^{\circ}$. Pero si, como sostiene Hegel, el tiempo es el concepto existente, entonces el hombre es también la existencia empírica del concepto ${ }^{51}$.

Ahora bien, la existencia empírica del hombre o del concepto en el mundo depende del hecho de que en este mundo haya tiempo empíricamente existente. Lo que a su vez depende de la existencia del deseo humano que busca realizarse. El deseo queda satisfecho al final de la historia, cuando ésta arriba al saber absoluto, es decir, al sabio o a la ciencia encarnada. Esta encarnación de la ciencia como existencia empírica en el mundo asume la forma de libro, a saber, el Sistema de la Ciencia que tiene como primera parte la "Ciencia de la Fenomenología del espíritu", y cuya segunda parte comienza con la Lógica de Hegel. El contenido de este libro es la totalidad del espíritu manifestada sensiblemente mediante letras impresas en hojas de papel que pueden ser leídos y comunicados a todos los hombres ${ }^{52}$. Aunque aparece en el tiempo es eterno, pues no puede ser escrito sino en el último momento del tiempo, que abarca su totalidad ${ }^{53}$. Al finalizar el tiempo, y por ende la historia, el espíritu vuelve a su punto de partida y restablece la identidad con el comienzo, sin la cual el movimiento de la historia no se habría podido iniciar. En este sentido, el tiempo es circular pero no cíclico. El círculo del tiempo no se puede recorrer más que una vez ${ }^{54}$. No hay recomienzo, pero sí hay recuerdo (Erinnerung) que interioriza el sentido de ese recorrido, lo comprende filosóficamente y lo expresa en forma de discurso escrito ${ }^{55}$. El espíritu se desprende del

49 Kojève, A. (1947), p. 367; CAA, pp. 128 s. Es notorio el contraste entre esta interpretación y la que Heidegger ofrece de la concepción hegeliana del tiempo, a la que contrapone la suya propia, que parece inspirar las interpretaciones de Koyré y Kojève. Ver De la Maza, L. Mariano (2010).

$50 \quad$ Kojève, A. (1947), p. 370; CAA, p. 133.

51 Kojève, A. (1947), p. 372, CAA, p. 135.

${ }_{52}$ Kojève, A. (1947), pp. 424-426; CAA, pp. 202-205.

53 Kojève, A. (1947), p. 386; CAA, p. 154.

$54 \quad$ Kojève, A. (1947), pp. 391 s.; CAA, pp. $160 \mathrm{~s}$.

55 Kojève, A. (1947), pp. 438- 441; CAA, pp. 221-224. 
hombre y pasa al libro, y con ello el movimiento dialéctico deja de ser movimiento de la historia y deviene movimiento del concepto ${ }^{56}$.

\section{La recepción de la lectura de Kojève}

\subsection{Hyppolite: singularidad y universalidad del espíritu}

La interpretación de Kojève ha tenido muchas y muy variadas repercusiones en Europa y Estados Unidos. Entre 1939 y 1941, apareció la primera traducción al francés de la Fenomenología del Espíritu, realizada por Jean Hyppolite, y en 1946 se publicó del mismo autor el comentario Génesis y estructura de la Fenomenología del Espíritu de Hegel. Posteriormente, en 1953, sale a la luz otro libro sobre la filosofía de Hegel, Lógica y Existencia. Si bien en una etapa inicial de su pensamiento fue influido por la lectura antropologizante de Kojève, da inicio a un cambio de orientación en la interpretación de la autoconciencia desde la centralidad de la dialéctica del amo y el esclavo hacia un enfoque marcado por el lenguaje.

En su comentario de 1946 afirma que la tarea de la Fenomenología es permitir que la conciencia individual capte el sentido universal de su tiempo y que, al mismo tiempo, y por ello mismo se eleve hasta un saber absoluto que sobrepase todo tiempo. Hyppolite se pregunta, como antes lo había hecho Koyré, acaso no hay aquí una contradicción. ¿Cómo puede la conciencia sobrepasar la temporalidad mediante el conocimiento de una verdad que es la conciencia de una determinada época de la historia? ¿Puede afirmarse que Hegel creyó ingenuamente que con su sistema de filosofía terminaba la historia? Afirma que esta sería una acusación injusta, y justifica esta afirmación con una cita tomada del Prefacio de la Filosofía del Derecho en la que Hegel asegura que es una locura imaginar que una determinada filosofía pueda superar su época, pues no puede hacer otra cosa que resumirla con su pensamiento ${ }^{57}$. Pero, por otra parte, esto no significa que el saber filosófico sea solamente pasajero y contingente, sino eterno ${ }^{58}$. En este punto, el problema de la relación entre la historia y el Saber absoluto se encuentra con la cuestión de cómo conciliar el punto de vista del espíritu finito que es el hombre con el del espíritu infinito o Dios. Según Hyppolite, Hegel tiene la respuesta clara: en la religión se reconcilian ambas cosas, el rebajamiento del espíritu infinito y la elevación del espíritu finito. El espíritu infinito o absoluto toma conciencia de sí mismo en el Hombre, y éste a su vez alcanza el Saber absoluto pensándose a sí mismo como Dios. En este sentido no hay en Hegel un panteísmo en el sentido vulgar, que hace desaparecer uno de los términos en aras del otro, o un misticismo en el cual la vida humana no es más 
que un momento de la vida divina ${ }^{59}$. Pero tampoco hay, según Hyppolite -y en esto se distingue claramente de la interpretación de Kojève- un humanismo que reduce a Dios al hombre, sino que mantiene más bien una cierta superación del hombre:

El espíritu absoluto supera al espíritu finito a pesar de lo cual sólo es gracias a él, si es cierto que únicamente en esta reconciliación (que supone la separación y la unidad) el espíritu es absoluto de modo auténtico en tanto que se hace tal ${ }^{60}$.

En su Lógica y existencia, Hyppolite afirma que el reconocimiento mutuo de las conciencias es el elemento fundamental del saber absoluto, pero añade que este reconocimiento se realiza en el elemento del lenguaje, y que el nexo entre lo particular y lo universal es el concepto o el sentido. El silencio o el aislamiento conducen a la disolución y la locura:

Es necesario confesar su acción, la manera particular de ser en el mundo, para conquistar su universalidad, para hacerla reconocer. Es necesario también acoger en sí la determinación particular del otro para elevarla a la universalidad, para promover a esta universalidad concreta, que es la unidad verdadera de lo singular y lo universal $[\ldots]^{61}$.

Por esta misma razón, es decir, por el énfasis en la búsqueda de una adecuada mediación entre universalidad y particularidad, Hyppolite presenta una visión más matizada de la admiración de Hegel por Napoleón que la de Kojève. Si bien reconoce la admiración por el genio y el sentido del Estado de Napoleón, señala, por otro lado, el hecho de que Hegel mantuvo cierta distancia respecto de su política imperial, por cuanto esta implicaba una fusión de las comunidades nacionales particulares y la pérdida de su individualidad.

Por otra parte, Hyppolite destaca que para Hegel una característica del mundo moderno es el desarrollo del individualismo bajo todas sus formas, que las instituciones políticas tratan de constreñir. En el origen de la conciencia de la individualidad está el principio de la subjetividad absoluta del cristianismo, es decir, el saber que el individuo tiene de su valor absoluto, saber que permanece encerrado en su subjetividad y contrapuesto al Estado. A esta tensión se refiere gran parte de la Fenomenología, por ejemplo, en los capítulos sobre el placer y la necesidad, la ley del corazón y el desvarío de la infatuación, la virtud y el curso del mundo. En el capítulo dedicado a la Revolución Francesa, Hegel considera ésta como un intento por superar la oposición entre el ciudadano libre y el Estado como realización de su voluntad objetivada. Sin embargo, la Revolución fracasa en ese intento y concluye en el terror y la anarquía, correspondiendo luego a Napoleón fundar el Estado moderno, como una realización de lo divino en la tierra. Hyppolite no estima, como Kojève, que con esta realización del Estado pueda decirse que la historia alcanza su fin y el sistema de Hegel, como

$59 \quad$ Hyppolite, J. (1998), pp. 490 ss.

60 Hyppolite, J. (1998), p. 492; ver Hyppolite, J. (1987), pp. 29, 53.

61 Hyppolite, J. (1987), p. 28; ver. 26 s. 
conciencia de lo absoluto, se cierre en un círculo definitivo. Su juicio es mucho más cauteloso:

[...] esta cuestión plantea el problema de la interpretación de conjunto de todo el sistema hegeliano; es fundamental para determinar, al fin de cuentas, el sentido del sistema. Sin embargo supera nuestra tarea, y no es evidente, por otra parte, que tenga siempre en nuestro filósofo una solución perfectamente neta. En su pensamiento subsiste una ambigüedad. Tal vez la reconciliación del espíritu subjetivo y el espíritu objetivo, síntesis suprema de este sistema, no sea totalmente realizable ${ }^{62}$.

\subsection{Bataille y Sartre: la desdicha de la autoconciencia}

Después de terminar su curso en 1939, condicionado por el comienzo de la Segunda Guerra Mundial, Kojève mantuvo escaso contacto con sus exalumnos, los que se redujeron aún más al ingresar a la Dirección de Relaciones Económicas Exteriores del gobierno francés, servicio en el que llegaría a ser uno de los principales impulsores del Mercado Común Europeo. Pero un alumno con el que sí permaneció en diálogo fue Georges Bataille. Bataille estaba tan convencido del valor de la repetición innovadora del pensamiento hegeliano realizada por Kojève ${ }^{63}$, que probablemente tomó como modelo para su propia apropiación del pensamiento de Nietzsche ${ }^{64}$. Antes de conocer la lectura de Kojève se había declarado en varios artículos como un rotundo antihegeliano, en particular de lo que consideraba su panlogismo. Sin embargo, un interés más positivo por Hegel se produjo cuando advirtió la posibilidad de contraponer su concepción de la dialéctica histórica a la dialéctica materialista de la naturaleza propiciada por Engels. Es desde esa perspectiva que descubrió en Kojève un aporte significativo a su propia reflexión ${ }^{65}$.

En 1955 y 1956, Bataille publicó dos artículos sobre el pensamiento de Hegel, que son más bien escritos acerca de la interpretación que Kojève hace de Hegel $^{66}$. En ellos se hace cargo de la interpretación kojèviana de la muerte, asociándola al concepto de sacrificio en un sentido amplio, que marcaría todo el movimiento de esta obra, y que significa la transformación del animal humano en hombre. Mediante

62 Hyppolite, J. (1970), p. 124.

63 Bataille, G. (2005), p. 8: "La originalidad y la valentía de Alexandre Kojève, hay que decirlo, están en el hecho de haber percibido la imposibilidad de llegar más lejos y la necesidad, en consecuencia, de renunciar a producir una filosofía original, y a eso se debe el interminable volver a comenzar que es la confesión de la vanidad del pensamiento" (Traducción corregida).

$64 \quad$ Ver Ebeling, Knut (2007), p. 61, nota 54.

$65 \quad$ Ver al respecto la trayectoria descrita por Raymond Queneau: "Primeras confrontaciones con Hegel, recogida en: Bataille, G. (2005), pp. 61-68.

66 Los artículos llevan por título: "Hegel, la muerte y el sacrificio", y "Hegel, el hombre y la historia”, ambos recogidos en: Bataille, G. (2005), pp. 11-58. 
el sacrificio, el hombre destruye al animal humano dentro de sí, dejando subsistir únicamente su verdad no corporal que lo hace un "ser para la muerte", según la expresión de Heidegger, que tanto Kojève como Bataille hacen suyas. Pero para que el hombre se revele a sí mismo como tal, debe representarse la muerte estando aún vivo. De allí surge "la necesidad del espectáculo o en general de la representación, sin cuyos ensayos podríamos, frente a la muerte, permanecer ajenos, ignorantes, como aparentemente lo están los animales" ${ }^{67}$. El arte, las fiestas, los espectáculos son formas de representación de la muerte o del sacrificio que evidencian, según Bataille, una conducta fundamental del hombre.

He vinculado el sentido del sacrificio a la conducta del Hombre una vez satisfechas sus necesidades de animal: el Hombre difiere del ser natural que él también es: el gesto del sacrificio es lo que él es humanamente, y el espectáculo del sacrificio pone entonces su humanidad de manifiesto. Liberado de la necesidad animal, el Hombre es soberano: hace lo que le place, su santa voluntad ${ }^{68}$.

Sin embargo, Bataille subraya una diferencia entre Hegel y el hombre del sacrificio, por el hecho de que aquél eleva a discurso consciente lo que para éste no es más que conocimiento sensible y oscuro. En este sentido, convierte el desgarramiento de la conciencia en algo pleno de sentido, aunque un sentido desgraciado. Ello implica, a juicio de Bataille, un empobrecimiento de la revelación extraída por el sabio de "la estancia en los lugares donde reina la muerte" ${ }^{69}$.

En lo que respecta al fin de la historia, Bataille la considera una verdad establecida, cuyo sentido es el paso de los hombres a la sociedad homogénea, en la que ya no realizan sucesivas modalidades humanas diferentes. La satisfacción del sabio es una frustración voluntaria y definitiva frente al hecho de que nada de lo que la humanidad piensa deja de deshacerse en polvo frente al poder devastador del tiempo. Al no buscar nadie una nueva diferencia, el hombre cede el sitio al ser animal completamente integrado en la naturaleza, sin negarla. Es la época de la cultura técnica, que vela por el cese de las distinciones cualitativas entre los hombres ${ }^{70}$, y que revela su impotencia para romper el curso del mundo ${ }^{71}$.

En El ser y la nada de Jean-Paul Sartre encontramos una semejante impotencia e infelicidad de la autoconciencia humana, aunque ahora a partir de una ontología dualista que en cierto modo había sido anticipada por Kojève cuando éste planteó que la tarea filosófica del futuro era justamente la elaboración de ese dualismo ${ }^{72}$. Sartre no asistió personalmente a los cursos de Kojève, pero se mantuvo informado sobre

67

68 Bataille, G. (2005), p. 31.

69 Bataille, G. (2005), p. 33; ver pp. 25 ss.

70 Bataille, G. (2005), pp. $51 \mathrm{s.}$

$71 \quad$ Bataille, G. (2005), p. 58.

72 Descombes, V. (1988), pp. 73 ss. 
ellos. La dualidad ontológica se expresa en su obra mediante la oposición entre el ser en-sí y el ser para-sí. El ser en-sí se define por la identidad, o por la pura positividad carente de relación, contingencia carente de fundamento, es lo que simplemente $\mathrm{es}^{73}$. Sin embargo, existe en el fenómeno en el que aparece, y no en otra parte, como la "cosa en-sí" kantiana. A su vez, el fenómeno aparece para una conciencia, que Sartre designa como el ser para-sí, que es diferencia y oposición, pura negatividad carente de identidad: es lo que no es y no es lo que es ${ }^{74}$. La conciencia no es en-sí, sino tan solo aquello donde lo en-sí aparece. En sí misma, la conciencia es nada.

Al igual que Kojève, Sartre vincula esencialmente la nada con la actividad humana de la negación del ser. La actividad libre que define al hombre como tal es el poder de negar o de "nihilizar" el ser en-sí singular. Como tal no es la nada en general, sino una privación igualmente singular, "que no es en modo alguno una sustancia autónoma"75. Según Sartre, la síntesis entre ambas regiones del ser es imposible, debido a que no existe equivalencia entre ellas. Mientras el para-sí depende del en-sí para poder ser la actividad negadora en que consiste, el en-sí puede ser sin para-sí y solo lo requiere para aparecer ante él en el fenómeno ${ }^{76}$. Pero para que el en-sí quisiera ser para-sí tendría que poseer algún grado de conciencia, lo que se descarta de antemano por definición. Por lo tanto, el paso de la subjetividad humana a una subjetividad absoluta ya no contrapuesta al en-sí está vedado.

La conciencia no solo se relaciona negativamente a lo en-sí, sino que también es conciencia de sí misma, es decir, autoconciencia. Ella se capta a sí misma como un sí-mismo, pero este sí-mismo no puede ser un en-sí, puesto que la conciencia no lo es. La autoconciencia es, pues, una nada que toma por objeto a una nada, una "faltaen-ser". Su manifestación óntica es el deseo. Pero a diferencia de la interpretación kojèviana del deseo, Sartre sostiene que el deseo no puede ser satisfecho jamás. En Sartre no hay espacio para un fin de la historia en el que el hombre alcance la satisfacción mediante la realización del reconocimiento. En este sentido el concepto hegeliano de la conciencia infeliz es reinterpretado como una realidad constitutiva e insuperable del hombre. La realidad humana aparece como tal en presencia de su propia totalidad como falta:

La realidad humana es padeciente en su ser, porque surge al ser como perpetuamente infestada por una totalidad que ella es sin poder serlo, ya que justamente no podría alcanzar el en-sí sin perderse como para-sí. Es, pues, por naturaleza, conciencia infeliz, sin trascender posible de ese estado de infelicidad ${ }^{77}$.

73 Sartre, J.-P. (1984), pp. $34-36$.

74 Sartre, J.-P. (1984), pp. 35, 113-118.

75 Sartre, J.-P. (1984), p. 639.

76 Sartre, J.-P. (1984), pp. 644 s.

77 Sartre, J.-P. (1984), p. 124. 


\subsection{Weil y Fukuyama: la satisfacción del reconocimiento}

Muy distinta es la consecuencia que extrae al respecto Eric Weil, uno de los más asiduos asistentes a los cursos de Kojève sobre Hegel. En su libro de 1950 sobre Hegel y el Estado, afirma que el "gran mérito del libro de Kojève es el haber hecho de los conceptos de reconocimiento y de satisfacción el centro de la interpretación del pensamiento hegeliano"78. Según Weil, "la satisfacción constituye el resorte último de la historia humana", pues le asigna su término, el que será alcanzado cuando cada individuo sea reconocido como valor absoluto por otro individuo, cuando sea y sepa que es miembro activo de la comunidad, y sepa además que es conocido y reconocido como tal por todos los demás y por el Estado mismo ${ }^{79}$.

Pero considera al mismo tiempo que los análisis de la Fenomenología del espíritu acerca de la dialéctica del amo y el esclavo constituyen solamente una prefiguración provisoria de estos temas, que solo alcanzan su verdadera concreción en la Filosofía del derecho de Hegel. En efecto, en esta obra Hegel expone de qué manera el Estado realiza la libertad del ser humano. No se trata de una forma particular de Estado ya existente, sino de una exigencia asociada a la idea de Estado como tal. Solo hay Estado allí donde todos los individuos que lo integran como ciudadanos alcanzan su satisfacción. La posibilidad de un Estado tal está acreditada por su efectividad (Wirklichkeit), en el sentido de que ejerce efecto sobre el desarrollo de las naciones que procuran realizarlo mediante un desarrollo progresivo. Ello vale también para el Estado prusiano en la forma que tenía en los tiempos inmediatamente posteriores a Napoleón, caracterizados por la búsqueda de una libertad institucionalizada. Otra cosa es la involución posterior de este proceso y la transformación del Estado prusiano en un sistema autoritario. No obstante lo cual la idea del Estado en sí sigue operando como una fuerza subterránea para retomar el rumbo de la progresiva realización de la libertad y satisfacción de sus miembros ${ }^{80}$.

Sí, Hegel 'justificó' el Estado moderno, el Estado representado por la Prusia de su época. Sí, Prusia fue quien produjo la conciencia de esta etapa del devenir del espíritu, de la realización de la libertad. Sí, Prusia está justificada en tanto que Estado del pensamiento, justificada y, por eso mismo, condenada. El espíritu se apresta a dar un nuevo paso ${ }^{81}$.

Lo que caracteriza al Estado moderno es el hecho de que en su organización no se presenta como una voluntad externa e incomprensible que oprime a los ciudadanos, sino que es su organización; son ellos quienes, sin abandonar su individualidad o sus intereses concretos, reconocen en la universalidad objetiva del Estado la realización de

Weil, E. (1970), p. 140, Nota 6.

Weil, E. (1970), pp. $76 \mathrm{~s}$.

Weil, E. (1970), pp. 129-134.

Weil, E. (1970), p. 133. 
esa voluntad e intereses. En ese sentido difiere esencialmente del Imperio romano, en el cual el individuo libre (no así el esclavo) es reconocido como persona privada, pero sin que llegue a formar parte del Estado, que se realiza únicamente en la persona del emperador ${ }^{82}$. Planteadas así las cosas, no es de extrañar que Weil considere que en el concepto hegeliano de negatividad, tal como fue desarrollado en la Fenomenología del espiritu, estén presentes todos los elementos del pensamiento revolucionario de Marx, aplicados por éste a los datos estructurales elaborados en la Filosofía del derecho ${ }^{83}$.

El mismo énfasis positivo en la satisfacción del reconocimiento se encuentra en la recepción que de la lectura kojèviana de la Fenomenología del espíritu realizada por Francis Fukuyama, quien fuera director adjunto de planificación política en el Departamento de Estado norteamericano. En un famoso ensayo publicado en 1989 en la revista National Interest, y posteriormente en el libro de 1992, titulado El Fin de la Historia y el último hombre, Fukuyama sostiene que la lucha por el reconocimiento es el motor de la historia, el cual, asociado a la lógica económica de la ciencia moderna, que empuja a los hombres a la satisfacción cada vez más amplia de sus deseos, conduce a la derrota de las tiranías de cualquier signo. Siguiendo explícitamente la lectura de Kojève, Fukuyama pone de relieve la importancia de Napoleón en la difusión del Estado liberal moderno que baja a la tierra el ideal cristiano de una sociedad libre e igual. Por otra parte considera que el pensamiento hegeliano representa una visión más noble y un reflejo más exacto de lo que es una sociedad liberal que la tradición del liberalismo anglosajón representado por Hobbes y Locke:

Si el liberalismo hobbesiano y lockeano puede interpretarse como la busca del interés propio racional, el 'liberalismo' de Hegel puede verse como la busca del reconocimiento racional, o sea, el reconocimiento a escala universal por el cual todos reconocen la dignidad de cada uno como un ser humano libre y autónomo ${ }^{84}$.

Fukuyama retoma también la interpretación de Kojève relativa al Estado homogéneo y universal como última etapa de la historia humana y sostiene que la afirmación de Kojève de que nos hallamos en el final de la historia se mantiene o cae según se mantenga o caiga la afirmación de que el Estado democrático liberal satisface adecuadamente el deseo humano de reconocimiento. Esa parece ser la convicción universal después de la caída del Muro del Berlín. Pero también señala que es necesario prestar la atención a un hecho que Kojève no consideró suficientemente, a saber, que "el surgimiento y duración

Weil, E. (1970), pp. 75 ss.

83 Weil, E. (1970), p. 140. A este respecto, Weil discrepa del juicio de Hyppolite acerca de la escasa influencia de Hegel sobre la Crítica de la Filosofía del derecho redactada por el joven Marx en 1843, pues estima que Hyppolite no considera suficientemente el carácter fragmentario de esta obra, ni aprecia adecuadamente los pasajes en que Marx reconoce la validez del análisis hegeliano. Weil se refiere al artículo de Jean Hyppolite: "La conception hégélienne del Etat et sa critique par Karl Marx”, en Cahiers internationaux de Sociologie, vol. II, $2^{\circ}$ année, Paris 1947, pp. 142 ss. Ver Weil, E. (1970), p. 143, Nota 10.

Fukuyama, F. (1992), p. 277. 
de una sociedad que encarne el reconocimiento racional parece requerir la supervivencia de ciertas formas de reconocimiento irracional", es decir, a formas premodernas o no universales de reconocimiento limitadas a grupos o intereses particulares ${ }^{85}$.

\subsection{Los problemas de estas interpretaciones}

Termino con algunas observaciones críticas respecto de esta línea de interpretación antropológico-existencial e histórico-política marcada por la lectura de Alexandre Kojève. No se puede decir que todos los comentarios posteriores a Kojève tengan el mismo grado de influencia o dependencia respecto de la lectura de éste. El caso de Jean Hyppolite es, entre todos los que hemos destacado, el que revela el más extenso y profundo conocimiento de la obra de Hegel, y seguramente por lo mismo es el más capaz de tomar distancia crítica de su maestro. En el otro extremo se encuentran los estudios de de Eric Weil y de Fukuyama. En un lugar intermedio se puede situar la posición de Bataille y de Sartre, quienes no tienen un interés primario en comentar la Fenomenología del espíritu, sino más bien sus conexiones con la filosofía del derecho y del Estado, en el primer caso, o con los conceptos centrales de una ontología fenomenológica dualista, en el segundo.

Establecido lo anterior, cabe decir que, con la sola excepción de Hyppolite, las lecturas resumidas en este artículo, adolecen, en lo que respecta a la comprensión de la filosofía de Hegel, de notorias insuficiencias y unilateralidades. Algunas de estas, en las que incurre también el mismo Hyppolite, dependen de factores casi inevitables en el tiempo en que fueron escritas, pues todavía los estudios filológico-críticos sobre la evolución de la obra de Hegel no tenían el grado de desarrollo que han alcanzado posteriormente con la edición histórico-crítica patrocinada por la Academia de la Ciencias de Renania del Norte-Westfalia. No obstante, a diferencia de los otros intérpretes comentados en este artículo, Hyppolite posee la suficiente agudeza y sagacidad para advertir la importancia que tiene para la Fenomenología del espíritu la correlación entre las figuras de la conciencia y las categorías de la Lógica ${ }^{86}$, y en general, la importancia que tiene para el Sistema de la filosofía de Hegel la mediación conceptual entre los términos contrapuestos que por un lado enriquecen la variedad y el dinamismo del espíritu y, por otro lado, amenazan con desgarrarlo en dicotomías insolubles.

Kojève no tiene razón cuando identifica el método fenomenológico de Hegel con la fenomenología de Husserl. El primero tiene una evidente dependencia de la concepción lógico-metafísica que está en la base de su Sistema, cosa que Husserl evita a cualquier precio. Tampoco acierta Kojève al sostener que la dialéctica es un método que solo debiera referirse al ser humano o espiritual y no a la naturaleza. Se comprende que ello ocurra en el contexto de una visión crítica de la dialéctica de la naturaleza propiciada por Engels, que ejerció una fuerte influencia en el ambiente intelectual 
francés del primer cuarto del siglo XX, pero el precio a pagar por querer introducir en la filosofía de Hegel un dualismo naturaleza-espíritu es demasiado alto, y no solo ajeno sino opuesto a la inspiración fundamental de esta filosofía, que se caracteriza por el afán de superar todas las contraposiciones de la reflexión o del entendimiento, entre las cuales la más significativa es justamente la que la filosofía moderna establece entre naturaleza y espíritu.

Por otra parte, no es adecuado distinguir entre un momento antropológico y un momento metafísico de la Fenomenología, como lo hace Kojève. Lo que hay más bien son dos estratos: un estrato lógico-metafísico, cuyas determinaciones o categorías se desarrollan de un modo que ocurre a "espaldas de la conciencia" 87 , y el correspondiente movimiento fenomenológico, o de la conciencia que pugna por superar su estado inicial diferente de dicho fundamento, y los distintos momentos de la "historia" o del camino de la conciencia hacia el saber absoluto en que dicha diferencia es definitivamente superada.

El camino de la conciencia se expone, a su vez, de dos maneras distintas, aunque complementarias. La primera corresponde a la división en capítulos, que se estructuran en torno a las distintas "figuras" de la conciencia, es decir, las distintas modalidades del saber que paulatinamente van siendo depuradas de su diferencia con la verdad, es decir, con el absoluto del que quieren dar cuenta sin conseguirlo cabalmente hasta llegar al capítulo final sobre el Saber absoluto. La segunda, en cambio, corresponde a una segunda división del libro en secciones estructuradas en torno a momentos generales del Espíritu: Conciencia, Autoconciencia, Razón, Espíritu inmediato, que finalmente son reunidos en la unidad totalizante de la Religión como autoconciencia del Espíritu que integra todos los momentos anteriores en el marco de la historia universal. A esta reunión de los momentos generales en la totalidad religiosa corresponde la metáfora de los "nudos" (Knoten) y el "haz" (Bund) que Hegel presenta en la introducción del capítulo sobre la Religión ${ }^{88}$. Finalmente, el capítulo sobre el Saber absoluto retoma la síntesis de la Religión y la reinterpreta en el lenguaje conceptual de la Filosofía, sin alterar lo esencial del contenido ya prefigurado en el capítulo anterior.

Nada de lo dicho aparece en la lectura de Kojève ni de los demás comentaristas, con la sola excepción parcial de Jean Hyppolite. En general tienden a considerar la Fenomenología, y en particular sus figuras, especialmente las correspondientes a la dialéctica del amo y el esclavo, como si se tratara de determinaciones del Sistema de Hegel y no de meros ejemplos propedéuticos introductorios al mismo, y por lo mismo solo parcialmente anticipatorias de aquello a lo que se espera llegar. El lugar propio del reconocimiento y sus distintos aspectos no es en realidad la Fenomenología, sino la tercera parte del Sistema, consagrada a la Filosofía del Espíritu. Si se traen a colación en la Fenomenología solo es a título de ilustración de otras relaciones más fundamentales que la conciencia natural, todavía no formada "científicamente", es decir filosófica- o especulativamente, no está en condiciones de asimilar sin estas ejemplificaciones. Por 
lo mismo, no se consideran en esta exposición propedéutica algunos aspectos esenciales de la concepción completa de la teoría del reconocimiento, como por ejemplo, las relaciones del amor o del derecho. Por otra parte, no se encuentra en Hegel la expresión "deseo de deseo", ni corresponde al sentido de su pensamiento.

Lo mismo cabe decir de las consideraciones de Hegel sobre la religión y la historia, que en la Fenomenología reciben un tratamiento muy parcial, en ningún caso equivalente a la teorías correspondientes en el sistema que es introducido por esta obra. La función de la religión es la de totalizar en un marco histórico universal todas las experiencias parciales desarrolladas en las figuras anteriores y proporcionarles un sentido integrado apropiado para ser asumido por un saber absoluto, una vez que esa totalidad de sentido sea depurada de los últimos vestigios de contingencia asociados a la historia en tanto que enfrentada a la conciencia como una objetividad exterior a ella.

De hecho, la referencia al fin de la historia (término que no se encuentra literalmente en Hegel, aunque se puede relacionar con cierto aspecto de su filosofía) no puede aludir, en el marco de la Fenomenología, a otra cosa que el hecho de que, una vez alcanzado en el Saber absoluto el nivel de la concepción especulativa de la historia, no cabe seguir considerándola como se ha hecho hasta antes de llegar a este punto, vale decir, como una sucesión de hechos meramente contingentes o fortuitos, cuyo sentido profundo se desconoce o solo se presume a la luz de puntos de vista particulares, incluidos los de la religión cristiana (en la medida en que ésta permanece referida a un futuro escatológico o a un Más Allá indeterminado). Según Hegel, la filosofía no se ocupa del futuro ni del pasado meramente contingentes, sino del presente en cuanto que aprehende del pasado lo esencial, es decir, lo necesario, que solo se puede reconocer como tal una vez que los acontecimientos han tenido lugar, como lo ilustra la célebre imagen del búho de Minerva, que Hegel ofrecerá posteriormente en el Prólogo de su Filosofía del Derecho. Por cierto que tampoco corresponde al pensamiento de Hegel la idea de un Estado homogéneo y universal, pues ello es incompatible con su reiterada afirmación del carácter diferenciado y del protagonismo cambiante de los Estados a lo largo de la historia ${ }^{89}$.

\section{Referencias bibliográficas}

Auffret, Dominique (2009), Alexandre Kojève. La Philosophie, l'Etat, la fin de l'Histoire. Paris 1990: B. Grasset. Traducción de Claudia Gilman con Prólogo de Germán García, Alexandre Kojève. La Filosofía, el Estado y el Fin de la Historia. Buenos Aires: Letra Gamma.

Bataille, Georges (2005), Escritos sobre Hegel. Traducción de Isidro Herrera. Madrid: Arena. 
Baugh, Bruce (2003), French Hegel. From Surrealism to Posmodernism. Nueva York/ Londres: Routledge.

De la Maza, Luis Mariano (1998), Knoten und Bund. Zum Verhältnis von Logik, Geschichte und Religion in Hegels "Phänomenologie des Geistes". Bonn: Bouvier.

(2004), Lógica, Metafísica, Fenomenología. La Fenomenología del Espiritu de Hegel como introducción a la Filosofía especulativa. Santiago de Chile: Ediciones Universidad Católica.

(2010), "La crítica de Heidegger al concepto hegeliano del tiempo", en Vanessa Lemm y Juan Ormeño, ed., Hegel, pensador de la actualidad. Ensayos sobre la fenomenología del espiritu y otros textos. Ediciones Santiago de Chile: Universidad Diego Portales, pp. 411-430.

Descombes, Vincent (1988), Le même et l'autre. Quarante-cinq ans de philosophie française:1933-1978. Paris1979: Editions de Minuit, trad. de Elena Benarroch, Lo mismo y lo otro. Cuarenta y cinco años de filosofía francesa (1933-1978). Madrid: Cátedra.

Ebeling, Knut (2007), “Alexandre Kojève. Ein Snobismus sans réserve”, en Ulrich Johannes Schneider, ed., Der französische Hegel. Berlin: Akademie-Verlag.

Fukuyama, Francis (1989), “The end of history?” The National Interest, Summer, pp. $1-18$.

(1992), The End of History and the Last Man. Free Press, New York 1992, trad. de P. Elias, El Fin de la Historia y el último hombre. Barcelona: Planeta.

Hegel, Georg Wilhelm Friederich (1939-41), Phénoménologie de l'esprit. Trad. al francés de Jean Hyppolite. Paris: Aubier, 2 vols.

(2010), Gesammelte Werke. Editados por la Rheinisch-Westfälischen Akademie derWissenschaften. Hamburg 1968ss.: Meiner, vol.IX:Phänomenologie des Geistes. Ed. por Wolfgang Bonsiepen y Reinhard Heede, 1980. Traducción de traducción de Antonio Gómez Ramos: Fenomenología del espíritu. Edición bilingüe. Madrid: Universidad Autónoma de Madrid/ABADA.

(1997), Enzyklopädie der philosophischen Wissenschaften im Grundrisse (1830). Editada por Friedhelm Nicolin y Otto Pöggeler. Hamburg 1969: Meiner. Traducción al español de Ramón Valls-Plana, Enciclopedia de las ciencias filosóficas. Madrid: Alianza.

(2004), Grundlinien der Philosophie des Rechts oder Naturrecht und Staatswissenschaft im Grundrisse. Theorie Werkausgabe. Edición de Eva Moldenhauer y Karl Markus Michel. Suhrkamp, Frankfurt a. M., 1976, vol. VII. Traducción de Juan Luis Vermal, Principios de la filosofía del derecho. Buenos Aires: Ed. Sudamericana.

Hyppolite, Jean (1970), Introduction a la Philosophie de l'histoire de Hegel. Paris, 1948: Lib. Marcel Rivière y Cie. Trad. de Alberto Drazul, Introducción a la filosofía de la historia de Hegel. Buenos Aires: CALDEN. 
(1987), Logique et existence. Essay sur la logique de Hegel. Paris 1961: PUF. Trad. de María Cristina Martínez Montenegro y Jesús Rodolfo Santander Iracheta, Lógica y existencia. Ensayo sobre la lógica de Hegel. Puebla: Universidad Autónoma de Puebla.

(1998), Genèse et structure de la Phénoménologie de l'esprit. Paris 1946. Montaigne, Trad. de Francisco Fernández Buey, Génesis y estructura de la Fenomenología del Espíritu. Barcelona: Península, $3^{\text {a }}$. ed.

Kojève, Alexandre (1947), Introduction à la lecture de Hegel. Paris: Gallimard. Trad. de Juan José Sebrelli, revisión a cargo de Alfredo Llanos, La dialéctica del amo y del esclavo en Hegel. Buenos Aires 2006, Leviatán (Sigla: DAE); La concepción de la antropología y del ateísmo en Hegel, Buenos Aires 2007, Leviatán (Sigla: CAA); La dialéctica de lo real y la idea de la muerte en Hegel, Buenos Aires 1984, La Pléyade (Sigla: DRIM); La idea de la muerte en Hegel. Buenos Aires 2003, Leviatán (Sigla: IMH).

Koyré, Alexandre (1971), Études d'histoire de la pensée philosophique. Paris: Gallimard.

Labarrière, Pierre-Jean y Jarczyk, Gwendolyne (1996), De Kojève a Hegel, cent cincuante ans de pensée hégéelianne en France. Paris: Albin.

López-Domínguez, Virgina (1996), "Hegel y Sartre, mediados por Kojève", Anales del seminario de historia de la filosofia $\mathrm{N}^{\circ}$ Extra 1, pp. 159-171.

Sartre, Jean-Paul (1984), L'étre et le neánt: Essay d'ontologie phénomélogique. Paris 1943: Gallimard. Trad. de Juan Valmar: El ser y la nada, ensayo de ontología fenomenológica. Madrid: Alianza.

Weil, Eric (1970), Hegel et l'Etat. Paris 1950, Vrin. Trad. de María Teresa Poyrazian, Hegel y el Estado. Córdoba: Nagelkop.

Wahl, Jean (1929), Le malheur de la conscience dans la philosophie de Hegel. Paris: PUF. 